\title{
When piloting health services interventions, what predicts real world behaviours? A systematic concept mapping review
}

\author{
Tavis Hayes ${ }^{1}$, Natasha Hudek², Ian D. Graham ${ }^{2,3}$, Doug Coyle ${ }^{1,3}$ and Jamie C. Brehaut ${ }^{2,3^{*}}$
}

\begin{abstract}
Background: Modeling studies to inform the design of complex health services interventions often involves elements that differ from the intervention's ultimate real-world use. These "hypothetical" elements include pilot participants, materials, and settings. Understanding the conditions under which studies with "hypothetical" elements can yield valid results would greatly help advance health services research. Our objectives are: 1) to conduct a systematic review of the literature to identify factors affecting the relationship between hypothetical decisions and real-world behaviours, and 2) to summarise and organize these factors into a preliminary framework.

Methods: We conducted an electronic database search using PsycINFO and Medline on November 30th, 2015, updated March 7th, 2019. We also conducted a supplemental snowball search on December 9th 2015 and a reverse citation search using Scopus and Web of Science. Studies were eligible to be included in this review if they clearly addressed the consistency between some type of hypothetical decision and a corresponding real decision or behaviour. Two reviewers extracted data using a standardized data collection form developed through an iterative consensus-based process. We extracted basic study information and data about each study's research area, design, and research question. Quotations from the articles were extracted and summarized into standardized factor statements.
\end{abstract}

Results: Of the 2444 articles that were screened, 68 articles were included in the review. The articles identified 27 factors that we grouped into 4 categories: decision maker factors, cognitive factors, task factors, and matching factors.

Conclusions: We have summarized a large number of factors that may be relevant when considering whether hypothetical health services pilot work can be expected to yield results that are consistent with real-world behaviours. Our descriptive framework can serve as the basis for organizing future work exploring which factors are most relevant when seeking to develop complex health services interventions.

Keywords: Real, Hypothetical, Decision making, Health services, Complex interventions, Systematic concept mapping review

\footnotetext{
* Correspondence: jbrehaut@ohri.ca

${ }^{2}$ Ottawa Hospital Research Institute, Clinical Epidemiology Program, The Ottawa Hospital, Ottawa, ON, Canada

${ }^{3}$ School of Epidemiology and Public Health, University of Ottawa, Ottawa,

ON, Canada

Full list of author information is available at the end of the article
}

(c) The Author(s). 2020 Open Access This article is licensed under a Creative Commons Attribution 4.0 International License, which permits use, sharing, adaptation, distribution and reproduction in any medium or format, as long as you give appropriate credit to the original author(s) and the source, provide a link to the Creative Commons licence, and indicate if changes were made. The images or other third party material in this article are included in the article's Creative Commons licence, unless indicated otherwise in a credit line to the material. If material is not included in the article's Creative Commons licence and your intended use is not permitted by statutory regulation or exceeds the permitted use, you will need to obtain permission directly from the copyright holder. To view a copy of this licence, visit http://creativecommons.org/licenses/by/4.0/. The Creative Commons Public Domain Dedication waiver (http://creativecommons.org/publicdomain/zero/1.0/) applies to the data made available in this article, unless otherwise stated in a credit line to the data. 


\section{Background}

In the quest to design new interventions to improve health care, health services research is routinely informed by studies and experiments that incorporate elements different from the real-world application. For example, when designing an intervention to reduce ordering of low-value tests in the ICU, the intervention may not be piloted only on ICU physicians within their day-to-day practice; instead, valid responses are expected to be obtained when data is collected outside of their day-to-day practice, or from non-ICU physicians, or from medical students. A parallel is often drawn with pharmaceutical trials, where prior to definitive trials, considerable preparatory research involves many 'hypothetical' elements, including animal models, pilot participants (e.g. patients, clinicians who may differ from the ultimate target group), hypothetical decisions (i.e. would you participate in a study like this?) and pilot settings (e.g. laboratories). The mechanisms studied in this preparatory research are expected to generalize to the ultimate clinical setting, despite these hypothetical or modeled elements, and such preparatory work is considered essential to the overall goal of designing interventions that will work safely and effectively in real clinical settings.

When developing health services interventions, pilot research can incorporate many hypothetical elements. As a multidisciplinary field that studies how personal, organizational, technological, and systemic factors affect access to, quality, and cost of health-care [1], health services research often seeks to design complex interventions [2] to encourage changes in behaviour and decision making among actors (patients, providers, decision makers) within the system. To aid development of these complex interventions, initial work can include piloting decision support tools on healthy volunteers rather than patients, measuring physician performance in simulated settings, and surveying or interviewing people about how they would behave under various hypothetical circumstances.

Despite these tools at our disposal, health services research interventions have often proceeded to large-scale trials without adequate preparatory or pilot research [25]. The most recent UK MRC Framework for complex interventions [2] explicitly emphasizes the need to pilot these interventions, in part to model the mechanisms by which one expects the intervention to work before proceeding to large, expensive trials. The reasons why there has been such a lack of preparatory work in health services research are unclear, and may stem in part from a naive sense of the ease with which such behaviours and decisions can be changed $[5,6]$. The study of the mechanisms underlying how health services interventions work is still relatively new $[5,7,8]$. Perhaps as an implicit reaction to the lack of understanding around this issue, there is a disciplinary distrust in pilot data that involve 'hypothetical' elements; systematic reviews often exclude studies involving hypothetical elements [9-11] without adequate justification.

We propose that understanding the conditions under which health services studies with 'hypothetical' design elements can yield valid results is essential to advancing health services research. With so many elements in these complex interventions, conducting full-scale trials of every permutation is essentially impossible; comparing different combinations in smaller pilot studies with hypothetical elements is inevitable and necessary. While other disciplines (e.g. economics, [12] moral reasoning, [13] social psychology [14]) have explored the conditions under which hypothetical decisions accurately reflect real-world decisions, little of this work has been applied to problems of health services intervention design. As an initial step towards understanding how such factors might be relevant to designing health services interventions, we conducted a systematic concept review of factors that have been shown to be related to the consistency between hypothetical and real-world decisions or behaviours. Based on these findings, we proposed a preliminary framework for those seeking to design a pilot process with hypothetical elements, which summarises and describes factors that may be related to ultimate validity with real-world behaviours.

\section{Methods}

We conducted a systematic concept mapping review, which we define as a review with a systematic search strategy that seeks to delineate the factors related to one or more target concepts; as such, the approach overlaps with systematic reviews and mapping reviews [15]. In this case, we sought to describe and map factors related to 'consistency', defined as the association between hypothetical decisions and corresponding real-world decisions or behaviours. In the context of this review, consistency is operationalized liberally as the association between 1) a hypothetical task or pilot task that includes some hypothetical elements, and 2) a corresponding, author-defined 'real-world' task, described in the same report. These might include actual real-world tasks or incentivized tasks that the authors claim to represent a 'real-world' decision or behaviour. Using the PICO approach to defining studies included in our review, [16] we define our population (P) to include any human study, our interventions (I) to include any factors affecting the relationship between real and/or hypothetical decisions, the comparison (C) to include real vs. hypothetical decisions or behaviours, and the main outcome $(\mathrm{O})$ to be the strength of consistency between those decisions/behaviours. 


\section{Search strategy}

We have modeled our reporting on the Preferred Reporting Items for Systematic Reviews and Meta-Analyses (The PRISMA Statement) [17]. Because the core issue has been explored in a variety of research areas, our review was designed to allow us to successfully obtain information from diverse fields. Two of the authors (TH \& JB) hand searched the literature to identify a set of target articles that could serve as the foundation for the review. The nine target articles all identified multiple factors that could affect the relationship between hypothetical and real tasks; all were indexed in PsycINFO and/or Medline [18-26]. A health science librarian helped us develop an initial search strategy that included all target articles and involved keyword and titles searches for 'decision making or behaviour', 'hypothetical situations', and 'real-world situations', including synonyms, relevant Medical Subject Headings (MeSH) headings, etc. This search strategy was peer reviewed by a second librarian and modified to develop the final search strategy (see Appendix A). Our search strategy development was guided by the Peer Review of Electronic Search Strategies (PRESS) guideline [27]. We conducted electronic database searches on November 30th, 2015 and March 7th, 2019, a supplemental snowball search on December 9th, 2015, and a reverse citation search using Scopus and Web of Science for studies that cited our target articles.

\section{Study selection}

We conducted a title and abstract screen on all records and liberally included those that might yield factors relevant to the framework; any unclear records were included for further screening. Two of three available reviewers $(\mathrm{TH}, \mathrm{JB}$, or $\mathrm{NH})$ independently screened the titles/abstracts for eligibility. The reviewers were not blinded to the journals or authors of the studies screened. To be included in the review, an article needed to clearly address the consistency between some type of hypothetical decision and a corresponding real decision or behaviour. Both empirical and commentary articles were included. Only studies published in English or in French were included. Studies were not excluded based on the setting, time frame, or the date of publication.

After title and abstract screening, the same three reviewers independently screened the full texts of the remaining studies. At this stage, studies were only included if they clearly presented a factor that would be relevant to the framework. The reviewers solved any disagreements through consensus, with JB acting as the final arbiter.

\section{Data extraction}

Three reviewers independently extracted data using a standardized data collection form and the consensus resolution processes described above. This form was developed iteratively during the screening and data collection process. They extracted basic study information (e.g. title, journal, date of publication) and data about each study's research area, design, and research question. Research area was coded into categories inductively. Design and research question were extracted verbatim from the articles. The type of data supporting the factor was coded as 1) review of multiple articles supporting the relationship (Review); 2) empirical support from a single study or related set of studies (Empirical), or 3) statement or hypothesis without empirical support (Hypothesis). Due to the heterogeneity of the included work in this broad concept mapping review (which included work from many disciplines, as well as empirical, review, and theoretical work), we could not assess the risk of bias in individual studies included in the review, the quality of empirical support underlying each factor, or the risk of bias across studies.

We identified factors presented in the study by selecting quotes that named and described the relevant factor. Two coders ( $\mathrm{TH}$ and $\mathrm{NH}$ ) extracted the quotes from each study to describe how the factor affected the consistency between hypothetical and real decisions. These quotations were then summarized to produce initial factor statements. A third person (JB) supervised and corroborated this coding.

\section{Data analysis and framework development}

Our approach to data analysis resembled what Hsieh \& Shannon (2005) call a "Conventional Content Analysis." [28] This inductive approach is useful when existing theory around a phenomenon being described is limited [28]. Based on the extracted study quotations and initial factor statements, we developed standardised statements describing each factor in terms of whether it was predicted to increase or decrease consistency. The coders then made collaborative decisions about when similar concepts were combined into a single factor. Where possible, we used the authors' own descriptions of the concepts to make these decisions.

As part of a preliminary framework development process intended to summarize and categorise the factor statements [29], raters made initial attempts at organizing the different factors into categories. After discussion yielded a mutually agreed upon set of categories that were thought to be largely mutually exclusive and potentially useful in thinking about how to design model studies, two coders (TH and JB) independently assigned each factor to a category; discussion resolved any conflicts. In situations where the sign of the association with consistency depended largely on phrasing (e.g. a positive association between consistency and 'certainty' might 
have been coded as a negative association between consistency and 'uncertainty'), coding was decided based on clarity and the manner of presentation in the original articles.

\section{Results}

Figure 1 describes the PRISMA flow diagram for our concept review. After duplicates were removed, the abstracts of 2444 articles were screened; 2344 of these were screened out as unrelated to the topic of consistency between real and hypothetical decisions or behaviours, or not published in English or French. The remaining 100 articles underwent full text screening; 24 were excluded for lack of any identifiable factor relating hypothetical and real-world decisions or behaviours, while another 8 were identified as being too 'context-specific', meaning they described factors that likely had limited application to health services interventions (e.g. 'intention to conduct criminal acts'), or because they were unrelated to consistency. The remaining 68 articles came from a range of literatures, including behavioural economics (44 articles), the

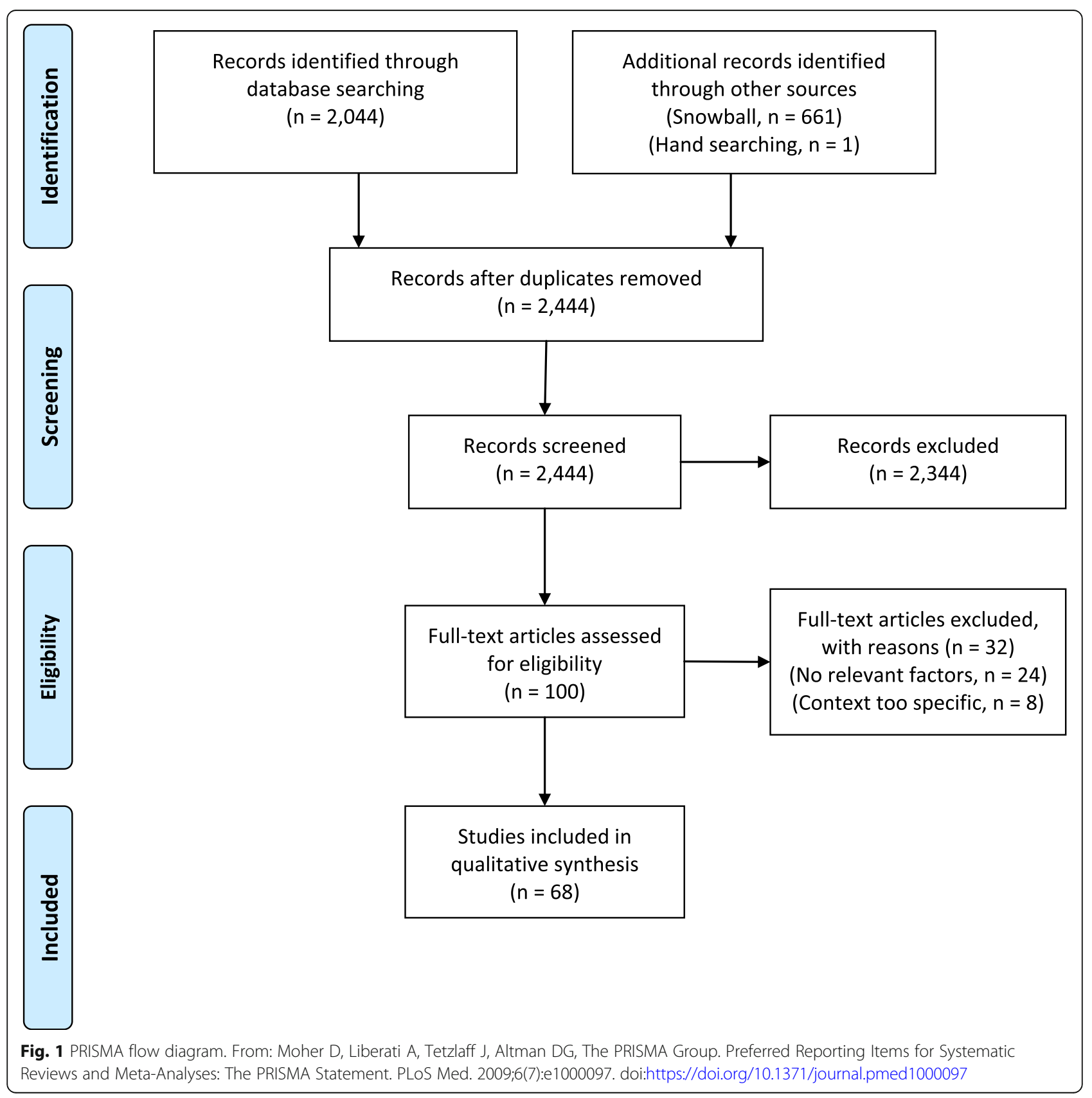


psychology of reasoning/behaviour (14 articles), social psychology (7 articles), health behaviours (4 articles), and neuroscience (5 articles). The 68 articles identified 27 factors purported to modify the relationship between hypothetical and real-world decision making. For details on the included articles see Appendix B. Our consensus process identified 4 categories of factors as described below. Tables 1, 2, 3 and 4 correspond to these 4 categories, and provide name and definition of the factor, its proposed specific relationship to consistency, type of data supporting the relationship, and corresponding citations.

\section{Decision maker factors}

Decision maker factors are those traits/capacities that relate directly to the decision maker themselves. Table 1 describes seven factors of the decision maker studied in relation to the extent to which hypothetical decisions will match real-world decisions/behaviours. Relatively little data supported an association with basic demographic factors; for example, we were unable to find any clear associations with sex or ethnicity; however, one study reported possible gender differences in their results [38]. More convincingly, another study reported greater consistency in willingness to pay donation decisions with

1) Greater age of the decision maker, and

2) Higher education of the decision maker, both in the context of willingness to pay decisions [30].

More work has explored the extent to which capacities of the decision maker affect consistency, including
3) Cognitive control (higher cognitive control associated with lower consistency), and

4) Cognitive ability (higher scores showing lower consistency). Both were based on EEG studies involving participants choosing between hypothetical or real lottery options [23, 25]. In these studies, those with greater cognitive capacity or control were hypothesized to incorporate a greater number of issues into their decision making, considerations that made them less risk averse in hypothetical situations than in real situations.

5) Thinking dispositions (e.g. enjoy challenging ideas), where one study argued that such dispositions are related to greater consistency [21].

Several studies also explored apparently complex relationships between personality traits and consistency, including

6) Openness to experience, where higher openness may be negatively related to consistency in the context of moral cooperation decisions; openness to experience was predictive of real (incentivized) decisions, but not hypothetical decisions [31, 32].

7) Neuroticism, agency, and anti-social attitudes, where traits have been explored in their association with inconsistency across real-world and hypothetical decisions [13, 32, 33].

\section{Cognitive factors}

Cognitive factors are characteristics related to the decisionmaking process. Table 2 describes the ten cognitive factors identified as related to consistency. Several factors suggested negative associations, including activation of

Table 1 Decision maker factors

\begin{tabular}{|c|c|c|c|}
\hline Factor & Definition & Association with consistency & $\begin{array}{l}\text { Type of } \\
\text { supporting data }\end{array}$ \\
\hline Age & Age of the decision-maker & $\begin{array}{l}\text { Older decision makers show more consistency between } \\
\text { hypothetical and real life decisions }\end{array}$ & Empirical [30] \\
\hline Education & Educational attainment of the decision-maker & $\begin{array}{l}\text { More educated decision makers show more consistency } \\
\text { between hypothetical and real decisions }\end{array}$ & Empirical [30] \\
\hline $\begin{array}{l}\text { Cognitive } \\
\text { Control }\end{array}$ & $\begin{array}{l}\text { The decision-makers use of mental processes to } \\
\text { concentrate and think }\end{array}$ & $\begin{array}{l}\text { Higher cognitive control is correlated to inconsistency } \\
\text { between hypothetical decisions and real decisions }\end{array}$ & Empirical [23] \\
\hline $\begin{array}{l}\text { Cognitive } \\
\text { Ability }\end{array}$ & Cognitive ability of the decision-maker & $\begin{array}{l}\text { Higher cognitive ability increases risk aversion for } \\
\text { hypothetical decisions but not for real life ones }\end{array}$ & Empirical [25] \\
\hline $\begin{array}{l}\text { Thinking } \\
\text { Dispositions }\end{array}$ & $\begin{array}{l}\text { Whether decision-makers have dispositions about } \\
\text { thinking that allow them to accept strategies to make } \\
\text { hypothetical reasoning resemble real-world reasoning }\end{array}$ & $\begin{array}{l}\text { Being in a state of prolonged doubt increases correlation } \\
\text { between hypothetical and real life decisions }\end{array}$ & Hypothesis [21] \\
\hline $\begin{array}{l}\text { Openness } \\
\text { to } \\
\text { Experience }\end{array}$ & $\begin{array}{l}\text { Measure of the decision-maker's openness to a variety } \\
\text { of ideas and experiences }\end{array}$ & $\begin{array}{l}\text { Greater openness to experience trait (IASR-B5) is } \\
\text { predictive of hypothetical decisions but not real ones }\end{array}$ & Empirical [31, 32] \\
\hline $\begin{array}{l}\text { Other } \\
\text { Personality } \\
\text { Traits }\end{array}$ & $\begin{array}{l}\text { Personality traits, other than openness to experience, } \\
\text { of the decision-maker }\end{array}$ & $\begin{array}{l}\text { Personality traits, especially extraversion low neuroticism, } \\
\text { and anti-social traits correlated with inconsistently be- } \\
\text { tween hypothetical and real life decisions }\end{array}$ & Empirical [13, 32-34] \\
\hline
\end{tabular}


Table 2 Cognitive factors

\begin{tabular}{|c|c|c|c|}
\hline Factor & Definition & Association with consistency & Type of supporting data \\
\hline Normative Beliefs & $\begin{array}{l}\text { Whether the decision-maker is thinking about what } \\
\text { important others would think about their decision }\end{array}$ & $\begin{array}{l}\text { Normative Beliefs are less likely to be } \\
\text { activated for hypothetical decisions than } \\
\text { for real ones }\end{array}$ & Empirical [35] \\
\hline Social Desirability & $\begin{array}{l}\text { Whether the decision-maker's decision is affected by } \\
\text { their desire to conform to the experimenter's beliefs }\end{array}$ & $\begin{array}{l}\text { Social desirability affects hypothetical } \\
\text { decisions more than real decisions }\end{array}$ & $\begin{array}{l}\text { Review }[36,37] \\
\text { Hypothesis }[13,38]\end{array}$ \\
\hline $\begin{array}{l}\text { Anticipated or } \\
\text { Forecasted } \\
\text { Emotions }\end{array}$ & $\begin{array}{l}\text { Whether people are predicting the emotions they } \\
\text { think they would feel when making a decision, versus } \\
\text { actually experiencing those emotions }\end{array}$ & $\begin{array}{l}\text { Emotions in hypothetical decisions are } \\
\text { forecasted more than in real life decisions }\end{array}$ & $\begin{array}{l}\text { Review }[14,37,39] \\
\text { Empirical }[19,40-42]\end{array}$ \\
\hline Deliberative Mindset & $\begin{array}{l}\text { Whether participants are evaluating the pros and cons } \\
\text { of different options, versus focussing on information } \\
\text { that is useful for them to complete a selected goal }\end{array}$ & $\begin{array}{l}\text { The deliberative mindset is used more in } \\
\text { hypothetical decisions than in real life }\end{array}$ & Review [14] \\
\hline Abstract Construals & $\begin{array}{l}\text { Whether the decision-maker is thinking about the } \\
\text { general features, versus thinking about the specifics } \\
\text { of a decision }\end{array}$ & $\begin{array}{l}\text { Abstract construals of problems are } \\
\text { employed more in hypothetical decisions } \\
\text { than in real life }\end{array}$ & $\begin{array}{l}\text { Review [14] } \\
\text { Empirical [43] }\end{array}$ \\
\hline $\begin{array}{l}\text { Attribute } \\
\text { Non-Attendance }\end{array}$ & $\begin{array}{l}\text { Whether the decision-maker neglects to fully consider } \\
\text { some of the attributes of a decision }\end{array}$ & $\begin{array}{l}\text { More attention is paid to the attributes of } \\
\text { a real decision than a hypothetical one }\end{array}$ & Empirical [44] \\
\hline Risk Aversion & $\begin{array}{l}\text { Whether the decision-maker prefers options that are } \\
\text { less likely, but have greater rewards, to options that } \\
\text { are definite but have smaller rewards }\end{array}$ & $\begin{array}{l}\text { Risk aversion is underestimated in } \\
\text { hypothetical decisions compared to real } \\
\text { life ones. }\end{array}$ & Empirical [24, 45-48] \\
\hline Implicit Associations & $\begin{array}{l}\text { Amount of automatic associations elicited in the } \\
\text { decision }\end{array}$ & $\begin{array}{l}\text { Consistency between real and } \\
\text { hypothetical decisions is worse with } \\
\text { more implicit associations present }\end{array}$ & Empirical [49] \\
\hline Certainty & $\begin{array}{l}\text { Whether the decision-maker is certain that their } \\
\text { hypothetical decision is the same as would be their } \\
\text { real-world decision }\end{array}$ & $\begin{array}{l}\text { A high degree of certainty about a } \\
\text { hypothetical decision makes it more likely } \\
\text { to be consistent with a real decision }\end{array}$ & $\begin{array}{l}\text { Review [50-52] } \\
\text { Empirical }[26,53-55]\end{array}$ \\
\hline $\begin{array}{l}\text { Salience of/ Concern } \\
\text { with the Decision }\end{array}$ & $\begin{array}{l}\text { Amount of importance placed on hypothetical } \\
\text { decision }\end{array}$ & $\begin{array}{l}\text { Greater engagement/concern associated } \\
\text { with greater consistency }\end{array}$ & Empirical [20, 22, 31, 56-59] \\
\hline
\end{tabular}

1) Normative beliefs, where real donation decisions were affected by consideration of what important others (e.g. family members) would think of their decisions in a way that hypothetical decisions were not [35];

2) Social desirability, where a review of the literature shows that the wish to be seen favourably by the experimenter is stronger for hypothetical than realworld decisions [36];

3) Anticipated or forecasted emotions, given the extensive literature that shows that people are poor at predicting how they will feel in the future; similar issues are discussed under related terms such as 'hot-cold empathy gap', $[19,40]$ or 'predicted vs expected utility' [39];

4) Deliberative mindset, where individuals making hypothetical decisions may be more likely to carefully weigh pros and cons than those making real-world decisions [14];

5) Abstract construals, where hypothetical decisions are more likely to involve consideration of general vs specific features of the decision [14];

6) Attribute non-attendance, where decision makers are more likely to consider all relevant attributes in real-world than hypothetical decisions [44];

7) Risk aversion, where decision makers are often more likely to choose safer courses of action in real-world as compared to hypothetical situations $[24,45,46]$;

8) Implicit associations, where a greater amount of automatic associations related to less consistency [49].

Our review also identified factors of cognition that suggest positive associations with consistency, including

9) Certainty, where decision makers who are more certain of their hypothetical decisions are more likely to be consistent with real-world decisions [25, 50, 53, 54];

10) Salience of or concern about the task, where increasing salience of the decision or task (e.g. by increasing incentives, making the task more interesting, ensuring self-benefit, etc.) can increase consistency [20, 22, 31, 56, 57].

\section{Task factors}

Task factors include aspects of the hypothetical decision being made, independent of the match with the real world decision scenario. Table 3 describes the eight characteristics of the hypothetical task identified as related to consistency. Factors include 
Table 3 Task factors

\begin{tabular}{|c|c|c|c|}
\hline Factor & Definition & Association with consistency & $\begin{array}{l}\text { Type of } \\
\text { supporting data }\end{array}$ \\
\hline High Stakes Rewards & The size of rewards/incentives being offered & $\begin{array}{l}\text { When large incentives are available, risk aversion } \\
\text { is higher for real life decisions than for } \\
\text { hypothetical decisions }\end{array}$ & Review $[60,61]$ \\
\hline Framing Effect & $\begin{array}{l}\text { Whether the decision is framed in a way that is } \\
\text { positive (i.e. gains) or negative (i.e. losses) }\end{array}$ & $\begin{array}{l}\text { The framing effect may be larger for hypothetical } \\
\text { decisions than for real life ones }\end{array}$ & Empirical [62] \\
\hline $\begin{array}{l}\text { Explicit Statements of } \\
\text { Uncertainty of Outcomes }\end{array}$ & $\begin{array}{l}\text { When estimates of the probability of the outcome } \\
\text { are explicitly presented to the decision-maker }\end{array}$ & $\begin{array}{l}\text { Providing statements about uncertainty increases } \\
\text { consistency between hypothetical decisions and } \\
\text { real life }\end{array}$ & Review [60] \\
\hline $\begin{array}{l}\text { Fundamental } \\
\text { Attribution Error }\end{array}$ & $\begin{array}{l}\text { Whether the decision is worded in a way that asks } \\
\text { the decision-maker what they would do or asks } \\
\text { what they think someone else should do }\end{array}$ & $\begin{array}{l}\text { Presenting the hypothetical decision with the } \\
\text { decision-maker as the actor (as opposed to an } \\
\text { observer) increases consistency between } \\
\text { hypothetical and real-world decisions }\end{array}$ & Empirical [63] \\
\hline Personal Relevance & $\begin{array}{l}\text { Whether the decision being made is one that } \\
\text { involves people with whom the decision-maker } \\
\text { has long-term relationships }\end{array}$ & $\begin{array}{l}\text { Personal relevance of a problem is correlated } \\
\text { with consistency between hypothetical and } \\
\text { real decisions }\end{array}$ & Empirical [64] \\
\hline Real Consequences & $\begin{array}{l}\text { Whether the decision has real consequences } \\
\text { for the decision-maker }\end{array}$ & $\begin{array}{l}\text { Having real consequences makes hypothetical } \\
\text { decisions more closely predict real-world ones }\end{array}$ & $\begin{array}{l}\text { Review } \\
{[37,51,52,65-67]} \\
\text { Empirical } \\
{[43,47,67-69]}\end{array}$ \\
\hline $\begin{array}{l}\text { Space for Mental } \\
\text { Simulation }\end{array}$ & $\begin{array}{l}\text { The degree to which the context of the decision } \\
\text { is left to the imagination }\end{array}$ & $\begin{array}{l}\text { Greater space for mental simulation associated } \\
\text { with lower consistency }\end{array}$ & Empirical $[18,70]$ \\
\hline Self-Image & $\begin{array}{l}\text { Whether the decision relates to the } \\
\text { decision-maker's self-image (e.g. related to } \\
\text { their ethical beliefs) }\end{array}$ & $\begin{array}{l}\text { Decisions related to self-image show less } \\
\text { consistency between hypothetical and } \\
\text { real-world decisions }\end{array}$ & $\begin{array}{l}\text { Review }[51,71] \\
\text { Empirical }[72]\end{array}$ \\
\hline
\end{tabular}

1) High-stakes rewards; two reviews of the literature have pointed to high stakes decisions as being negatively associated with consistency- the higher the stakes, the lower the association between hypothetical and real $[60,61]$.

2) Framing bias (i.e. biases in decisions produced by providing outcome probability statements in terms of positive vs. negative frames) showing that this effect is more powerful for hypothetical than real-world decisions, reducing consistency [62].

3) Explicit Statements of uncertainty of outcomes, where having explicit statements describing the range of uncertainty around outcome estimates in the hypothetical task has been shown to be positively associated with consistency [60].

4) Fundamental attribution errors, where describing the decision maker as the direct actor, as opposed to an observer in the hypothetical task may be positively associated with consistency [63].

5) Personal relevance, where ensuring that the hypothetical task involves people the decision maker actually knows may be positively associated with consistency [64].

6) Real consequences, where ensuring that the hypothetical task entails actual consequences for decision makers is positively associated with consistency $[51,68]$.

7) Space for mental simulation (i.e. the degree to which the context of decision making is left to the imagination) may be associated with lower consistency $[18,70]$.

8) Self-image, where several studies have explored the notion that moral decisions may have lower consistency, given the tendency to preserve a positive view of oneself (i.e. more likely to make

Table 4 Matching hypothetical and real-world tasks

\begin{tabular}{lll}
\hline Factor & Definition & Association with consistency \\
\hline $\begin{array}{l}\text { Matching } \\
\text { Samples }\end{array}$ & $\begin{array}{l}\text { Whether the sample of people making the } \\
\text { hypothetical decision closely resembles the } \\
\text { population that faces the real-world decision }\end{array}$ & $\begin{array}{l}\text { When participants in hypothetical situations } \\
\text { resemble the target real-world group, hypothetical } \\
\text { decisions are more consistent with real-world ones }\end{array}$ \\
$\begin{array}{l}\text { Matching } \\
\text { Procedures }\end{array}$ & $\begin{array}{l}\text { Whether the study procedures (e.g. What decision } \\
\text { is being made and how the information is presented) } \\
\text { for both hypothetical and real tasks are matched. }\end{array}$ & $\begin{array}{l}\text { When the procedural characteristics of a } \\
\text { hypothetical decision resemble the real-world } \\
\text { decision, consistency will be higher }\end{array}$ \\
\hline
\end{tabular}


positive choices in hypothetical decisions than in real life) $[51,71,72]$.

\section{Matching hypothetical and real-world tasks}

Table 4 describes two related issues identified as increasing consistency by matching the hypothetical and real-world in different ways. These literatures discussed issues of consistency less directly, and as such coders were less able to identify specific tests of the relationship between consistency and individual factors. Coders felt that these issues were core to the issue of consistency despite the lack of explicit relationships, hence the inclusion of these issues.

1) Matching samples with the real-world population has been discussed extensively in various literatures. Many have argued that representative samples are essential in increasing consistency (e.g. Hainmueller et al., 2015, Kesternich et al., 2013 [56, 73]) and an extensive literature has explored the extent to which specific types of samples yield generalizable results (e.g. Berinsky et al., 2012, Peterson et al., 2014 [86, 87]). One study examining the validity of different survey designs in determining immigrant acceptance decisions demonstrated that samples that demographically reflected the target group matched real-world decisions more closely than did a sample of students [56]. Reviews of the extensive literature on the use of college students as subjects in social science experiments have shown that student samples often do not yield results that are reproducible in broader populations $[61,88]$. Note that we did not find any studies that sought to describe what patient characteristics need to be matched in order to ensure validity with a real-world health study.

2) Matching study procedures to the real-world decision contexts has also been explored extensively. Studies varying apparently minor deviations of the hypothetical decision-making context (e.g. number of cues, order of presentation) have often shown effects on complex decisions; matching on as many of these cues as possible has been argued to increase consistency [76]. For example, considerable work has examined delay discounting, i.e. the rate at which a good (or a health benefit) decreases in value depending on the amount of delay in receiving it. Chapman (2004) [39] discusses discounting in the context of health behaviours, like addiction. While most agree $[69,77]$ that the rate of delay discounting is generally consistent between hypothetical and real-world situations, [39, 7783] matching the decision-reward delay between hypothetical and real decisions improves consistency even further [84]. In a study of children's reactions to social problems, authors argued that having more time to decide in the hypothetical than the real situation would reduce consistency [85]. Other study authors have argued that matching contextual features of the hypothetical task to the real-world decision as closely as possible is essential for generalizable results $[69,89]$. This concept has been taken one step further, where authors argue the overall complexity of the decision environment in real-life situations becomes oversimplified in hypothetical choices, leading to poor choice consistency [74].

\section{Discussion}

If the health services research community is to systematically implement recommendations for better modelling prior to large scale interventions, [90] we need to understand how health care decisions and behaviours can most effectively be modelled. Given that most health service interventions seek to change the decisions or behaviours of different actors within the system (e.g. physician test ordering, patient participation decisions), we must design model studies in which hypothetical decisions/behaviours can be valid indicators of their real-world counterparts. In this review, we sought to summarize what is known about factors thought to affect the relationship between hypothetical and real-world decisions. Our review of 68 articles identified 27 factors shown or hypothesized to affect the relationship between hypothetical and real-world decisions/behaviours. Coming from a wide range of literatures, including behavioural economics, psychology of reasoning, social psychology, health behaviours, and neuroscience, these findings clearly underline the fact that much is already known about how to help decisions and behaviours made in hypothetical contexts reflect real world decisions. Equally clear is that relatively little of this discussion has focused on health behaviours (4 of 68 articles), further underlining the need to explore these issues for health decisions.

Figure 2 summarizes our descriptive framework of the four categories of factors identified to be related to consistency; i.e. whether hypothetical decisions will predict real-world behaviours. Above the center line are examples from each category that are positively associated with consistency; below the line indicates negative associations. Decision maker factors include specific trait-level descriptors that vary 


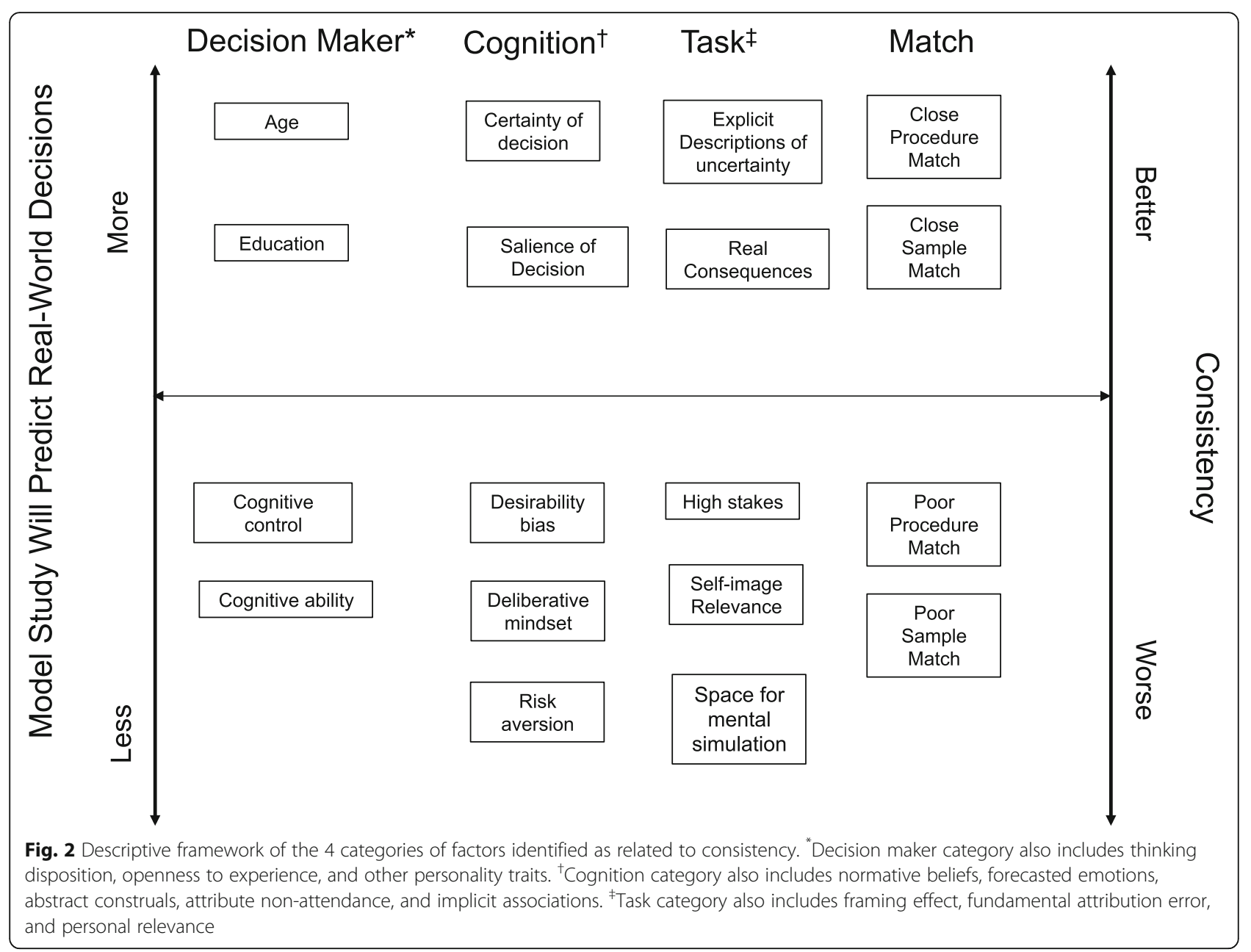

between (but usually not within) individuals, and may be positively (e.g. age, education) or negatively (e.g. cognitive ability) associated with consistency between hypothetical and real decisions/behaviours. Cognitive factors describe internal, context-dependent factors (e.g. certainty, risk aversion) that may affect human decision making in general, but are particularly relevant to hypothetical-real consistency. Task factors include important aspects of the hypothetical task (e.g. describes the uncertainty of outcomes, involves real consequences) that are related to consistency independent of their relationship to the real-world task. Finally, matching factors identify areas where an overall increase in similarity between the model situation and the real-world (sample matching, procedure matching) would be expected to improve consistency; a more fine-grained analysis of these two categories will be required to identify specific factors within the context of overall complexity of the environment.
We offer this draft framework not as a recipe for optimal design of model health care studies, but as a way of organizing and describing the range of factors that might need to be explored to achieve this end. The extent to which any individual factor will predict consistency in the context of health services decisions/behaviours is almost entirely open to debate at this early stage. Few of these factors have been tested in a health services context (but see Appendix B for examples of matching procedures, [39, 65, 81] real consequences, [65] degree of certainty, [53] and forecasting emotions [39]). The potential for interactions between factors in affecting consistency is almost entirely unexplored. The data supporting them at all are highly variable, ranging from extensive literatures summarized by systematic review to suppositions made without any empirical support. For this initial description, we chose to include all factors regardless of the level of empirical support or potential for bias in order to provide the greatest range of hypotheses to consider as we push this area forward. 
Several limitations of this work warrant consideration. First, while our search strategy sought to encompass as many synonyms for 'hypothetical' and 'real-world' decisions as possible, there are likely studies touching on this issue that were not captured by our search. For example, our search strategy did not include keywords specific to simulation teaching methods in the healthcare field. While the consistency between real and hypothetical decisions is relevant to the medical education field, that literature focuses on methods to help students make the 'right' decision (e.g. how objective structured clinical exams predict correct medical decisions). In contrast, our review focused on aspects of hypothetical decisions and their consistency with a real world decision independent of its 'correctness'. Second, many of the included studies from the behavioural economics literature involved the common practice of using incentives to distinguish hypothetical vs realworld decisions; a 'real-world' task implied one where participants were incentivized with tangible rewards, while hypothetical tasks involved no incentives. Although using incentives is known to increase motivation for a range of health behaviours, [91, 92] we do not know the extent to which simple incentives can serve as a model for complex, high-stakes, often emotion-laden health care decisions. On a related note, for this initial multi-discipline concept review, we could not assess the degree to which 'realworld' tasks were 'real' enough; instead, we took the authors' word that providing a $\$ 5$ incentive (for example) was an effective approach for modeling realworld decisions. Third, our initial framework is meant to be descriptive and does not attempt to identify relative importance of the described factors, or the causal relationships and interactions between them (as it does not constitute a theory). Fourth, we cannot make strong claims about the strength of the data underlying any particular factor and its relationship with consistency; while we sought to distinguish factors supported by considerable empirical support vs those without, a stronger assessment of the quality of evidence supporting the individual relationships, and the risk of bias associated with these varied studies, was beyond our resources. Therefore, as new research becomes available, future work should focus on a meta-analytic review of empirical studies to evaluate the risk of bias for the factors we have identified, as well as establishing statistical significance of these factors in predicting the consistency between real and hypothetical decisions and behaviours. Finally, we note that some of the identified factors (e.g. forecasting emotions, matching sample factors) are supported by substantial literatures and considerable theoretical discussion that provide a level of nuance we could not address in this review. The implications these non-health literatures have for health services research applications is a clear area of future work.

\section{Conclusions}

This review identifies a range of factors that may be relevant in determining when hypothetical pilot work can be expected to yield results that are consistent with real-world health services behaviours. We have highlighted four categories that appear to encompass these factors, categories that may be helpful to consider for those designing pilot health services work. Future work can use our list of factors as the range of hypotheses that must be tested to determine which factors are most important in determining consistency in a health services context. In health services research, it is rare that hypothetical work is reported in the same article with real-world trial results. Compiling health services research programs where hypothetical pilot work can be matched to reports of real-world outcomes would be a useful step in understanding when and how to maximize the utility of hypothetical health services research.

\section{Appendix A}

Search Strategy for PsycINFO and OVID MEDLINE (R)

ALL

Terms for decision making or behaviour:

1. Decision Making/ (156670).

2. Choice Behavior/(48,223).

3. reasoning.ti,ab. [No MeSH term] (56346).

4. Behavior/ (53175).

5. (decision* or choos $^{*}$ or choice ${ }^{*}$ or behavio? $\left.\mathrm{r}^{*}\right)$.ti,ab. (2851118).

6. Risk-Taking/ (37079).

7. (tak* adj2 risk*).ti,ab. (19838).

8. or/1-7 (2965585).

\section{Terms for hypothetical situations:}

9. Uncertainty/ (18393)

10. hypothetical ${ }^{*}$.ti,ab. (47294).

11. proxy.ti,ab. (25748).

12. (formal adj3 (reasoning or thinking or decision*)).Ti,ab. (1459)

13. or/9-12 (92440).

\section{Terms for real world situations:}

14. Reality/ (4401).

15. (real or reality).ti,ab. (554361).

16. everyday.ti,ab. (74373).

17. or/14-16 (623798).

18. 8 and 13 and 17 (2044)

19. remove duplicates from 18 (1782) 


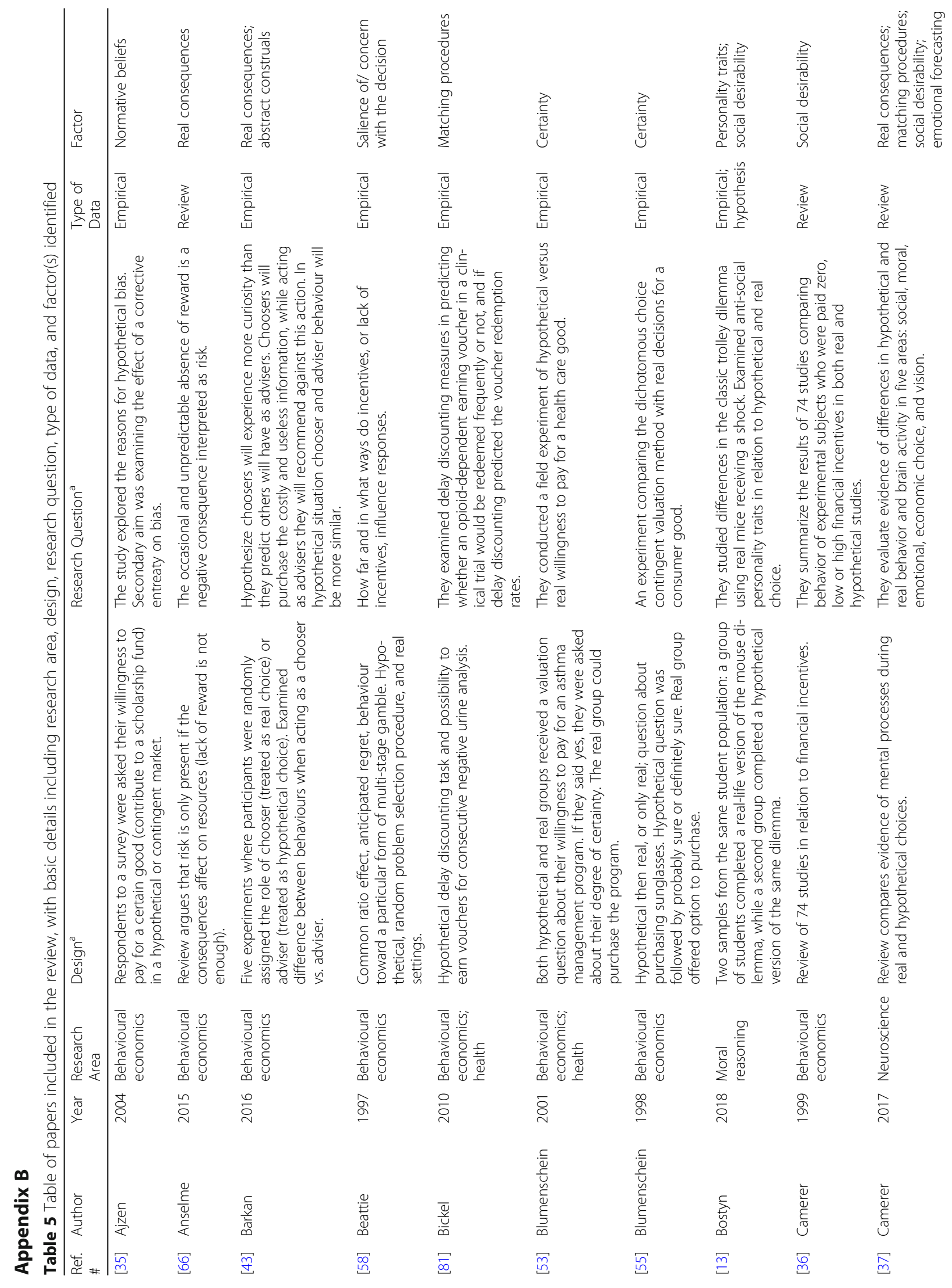




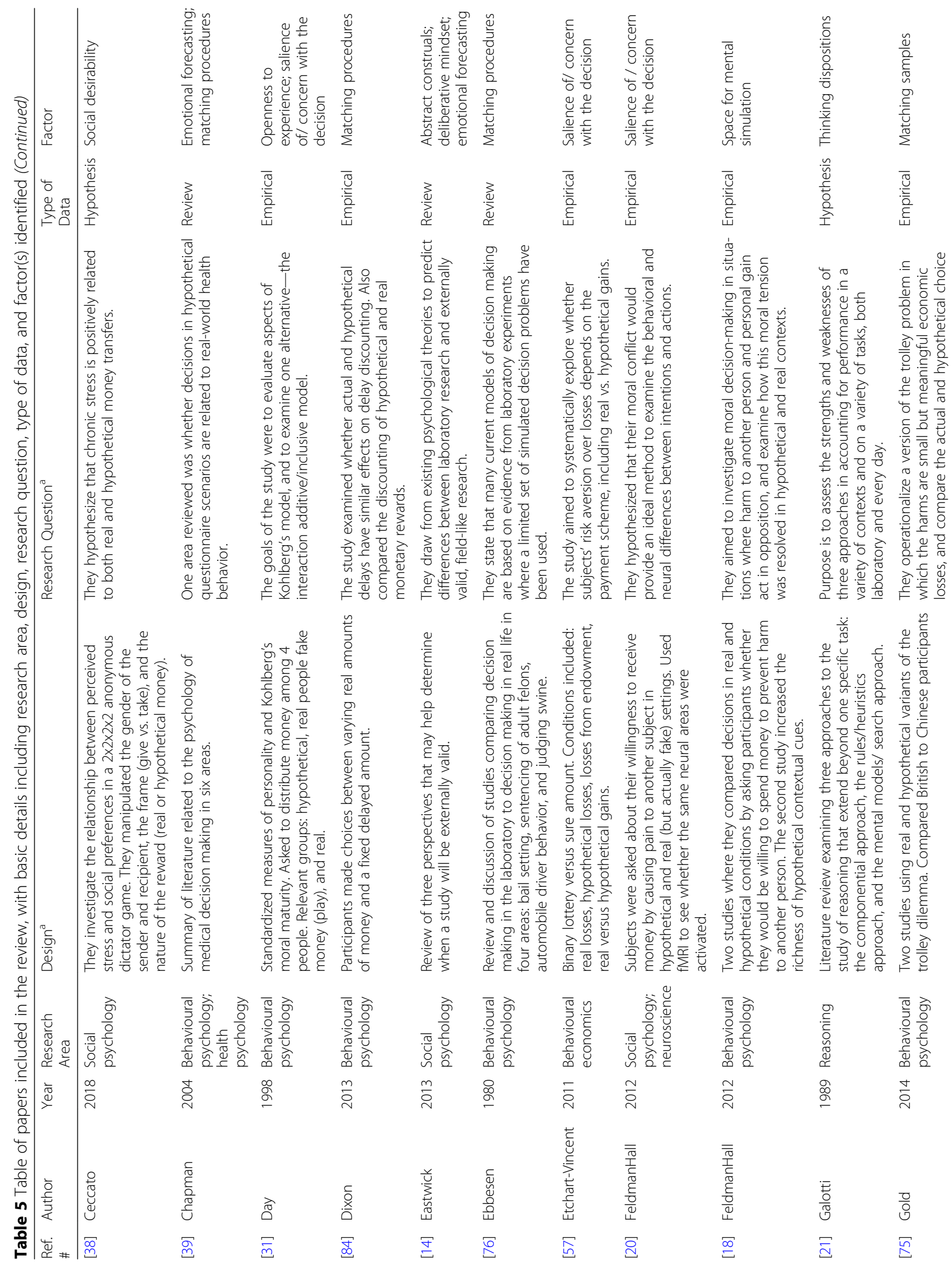




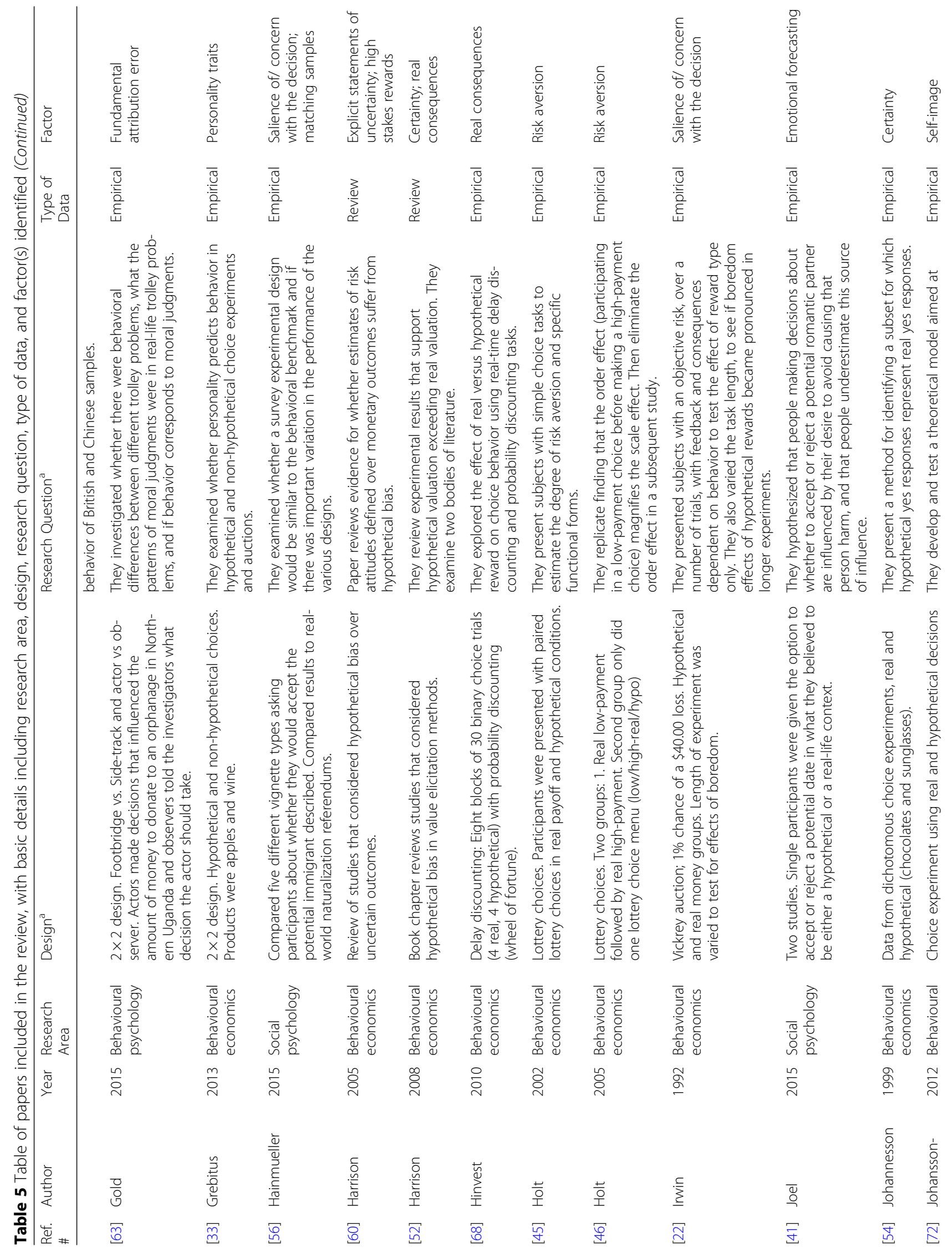




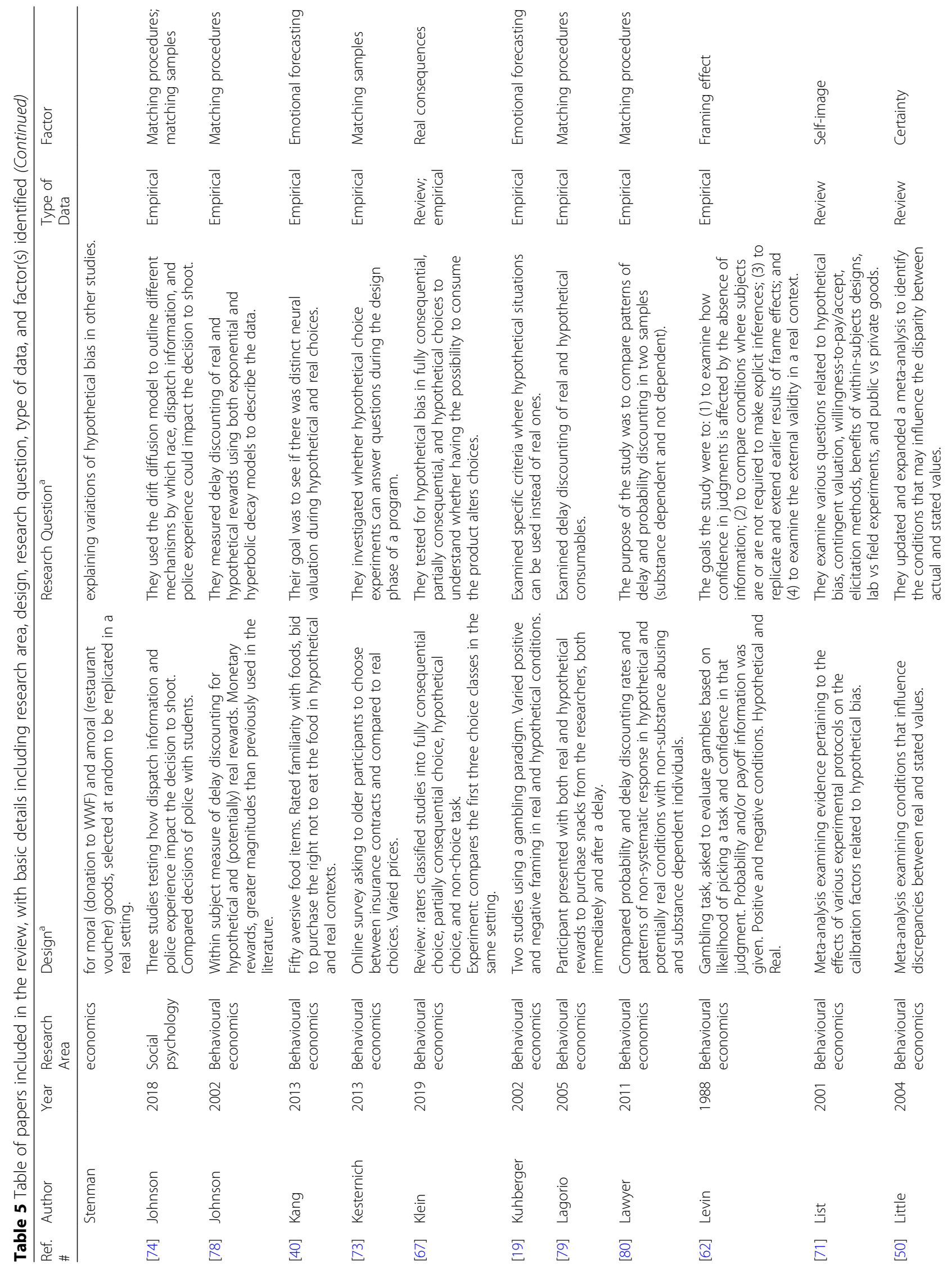




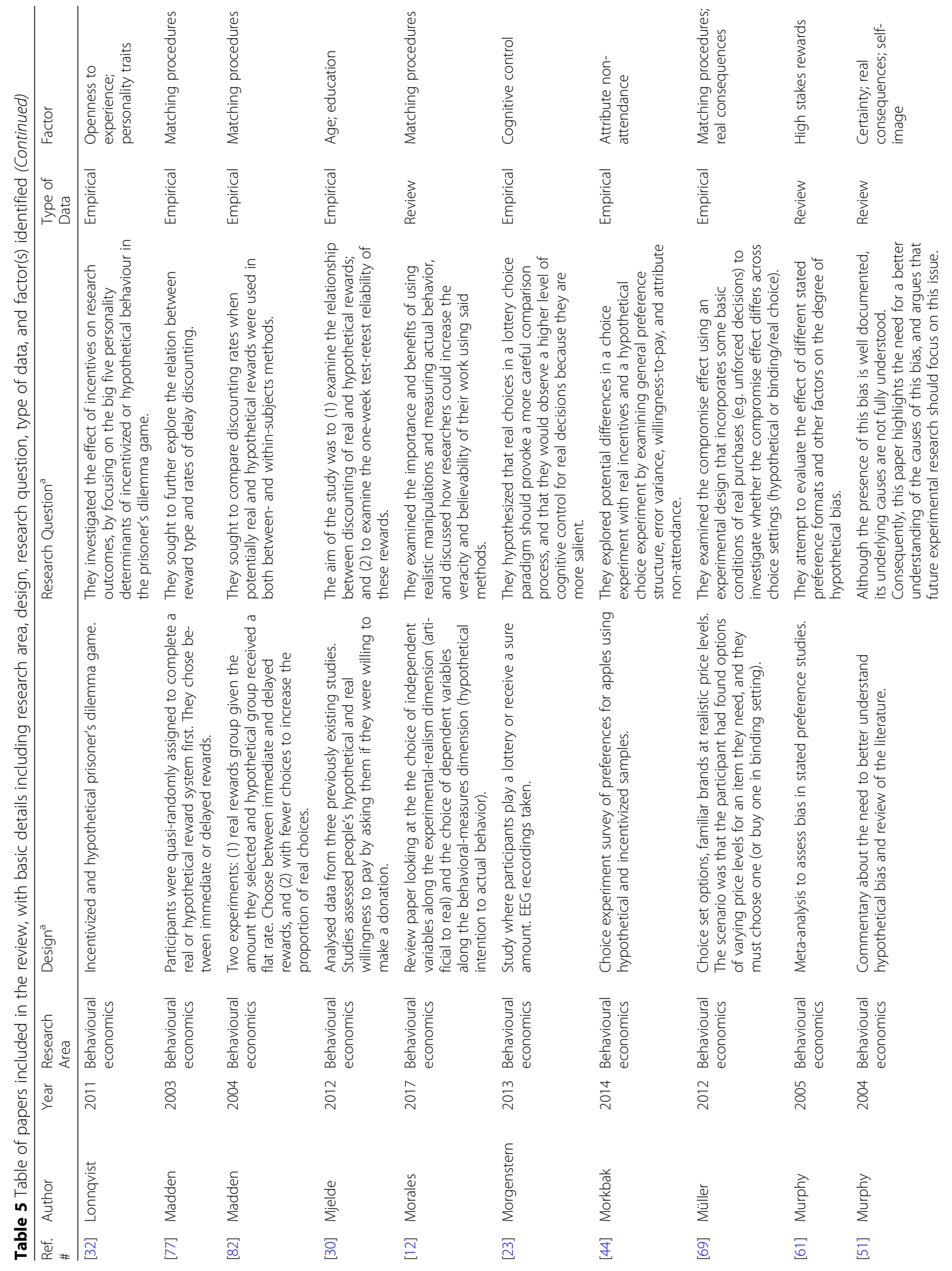




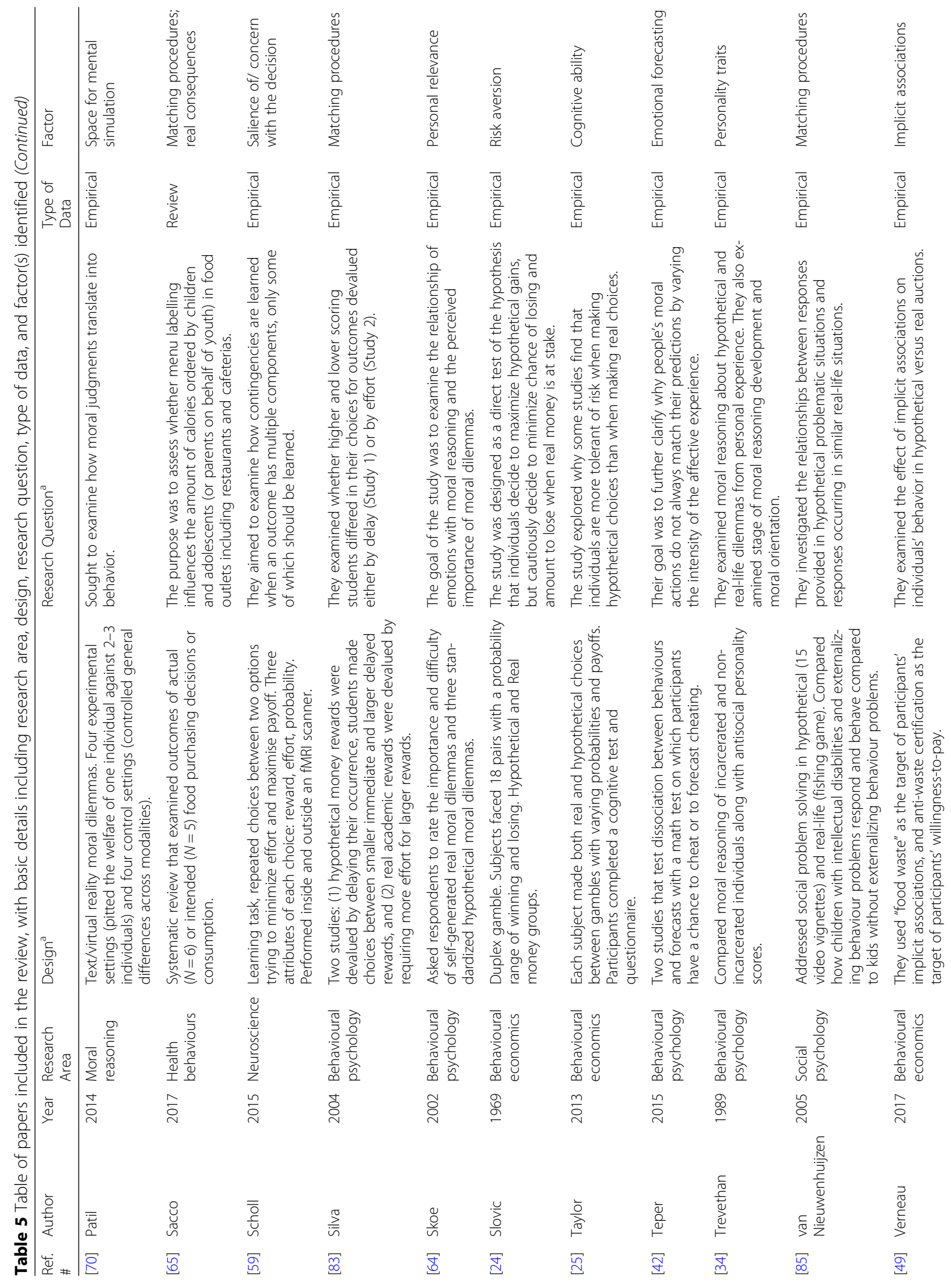




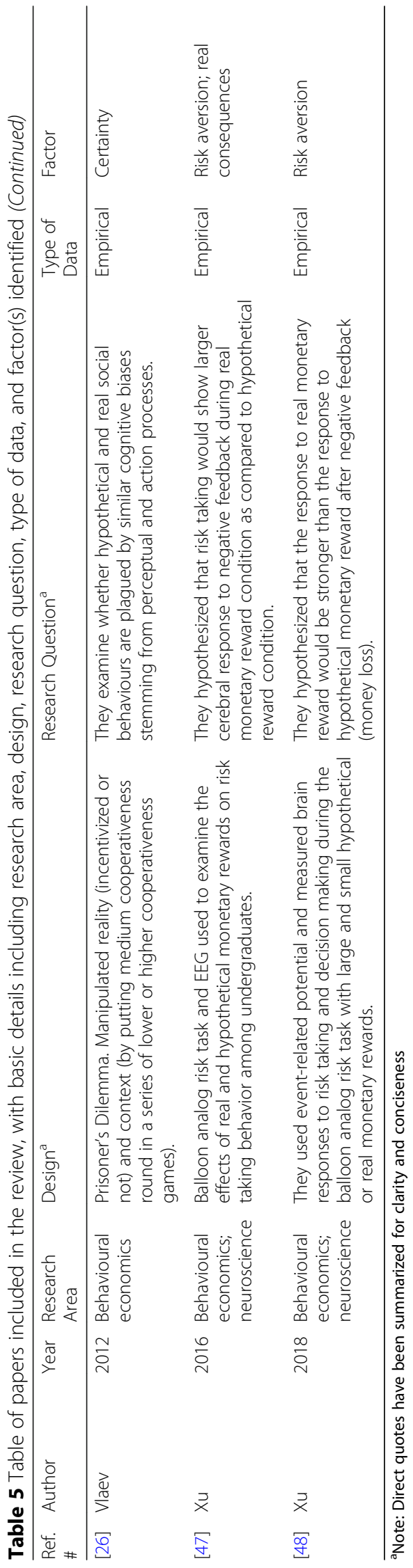




\section{Abbreviations}

PRISMA: Preferred Reporting Items for Systematic Reviews and MetaAnalyses; MeSH: Medical Subject Headings

\section{Acknowledgements}

Not applicable.

\section{Authors' contributions}

JCB informed the design of the study, screened articles and extracted data, conducted analyses, contributed to and approved the final draft of the manuscript. TH informed the design of the study, screened articles and extracted data, conducted analyses, contributed to and approved the final draft of the manuscript. $\mathrm{NH}$ screened articles and extracted data, conducted analyses, contributed to and approved the final draft of the manuscript. IG informed the design of the study, contributed to and approved the final draft of the manuscript. DC informed the design of the study, contributed to and approved the final draft of the manuscript.

\section{Funding}

This study was not funded, however IDG is a recipient of a Canadian Institutes of Health Research Foundation Grant (FDN \#143237) and TH was supported by an Ontario Graduate Scholarship (2015-2016).

\section{Availability of data and materials}

The data generated and used during the current study are available from the corresponding author on request.

\section{Ethics approval and consent to participate}

Ethics approval and consent to participate were not required for this review.

\section{Consent for publication}

Not applicable.

\section{Competing interests}

The authors declare that they have no competing interests.

\section{Author details}

${ }^{1}$ Faculty of Medicine, University of Ottawa, Ottawa, ON, Canada. ${ }^{2}$ Ottawa Hospital Research Institute, Clinical Epidemiology Program, The Ottawa Hospital, Ottawa, ON, Canada. ${ }^{3}$ School of Epidemiology and Public Health, University of Ottawa, Ottawa, ON, Canada.

\section{Received: 10 October 2019 Accepted: 19 March 2020}

\section{Published online: 06 April 2020}

\section{References}

1. Lohr KN, Steinwachs D. Health services research: an evolving definition of the field. Health Serv Res. 2002;37(1):15-7.

2. Craig P, Dieppe P, Macintyre S, Michie S, Nazareth I, Petticrew M, et al. Developing and evaluating complex interventions: the new Medical Research Council guidance. BMJ. 2008:337:a1655.

3. Campbell M, Fitzpatrick R, Haines A, Kinmouth AL, Sandercock P. Framework for design and evaluation of complex interventions to improve health. BMJ. 2000;321:694-6.

4. Campbell NC, Murray E, Darbyshire J, Emery J, Farmer A, Griffiths F, et al. Designing and evaluating complex interventions to improve health care. BMJ. 2007;334:455-9.

5. Eccles M, Grimshaw J, Walker A, Johnston M, Pitts N. Changing the behavior of healthcare professionals: the use of theory in promoting the uptake of research findings. J Clin Epidemiol. 2005;58:107-12.

6. Atkins L. Using the behaviour change wheel in infection prevention and control practice. J Infect Prev. 2016;17(2):74-8.

7. Colquhoun HL, Brehaut JC, Sales A, Ivers N, Grimshaw J, Michie S, et al. A systematic review of the use of theory in randomized controlled trials of audit and feedback. Implement Sci. 2013;8:66.

8. Durand MA, Stiel M, Boivin J, Elwyn G. Where is the theory? Evaluating the theoretical frameworks described in decision support technologies. Patient EducCouns. 2008;71(1):125-35.

9. Stacey D, Legare F, Col NF, Bennett CL, Barry MJ, Eden KB, et al. Decision aids for people facing health treatment or screening decisions. Cochrane Database Syst Rev. 2014;1:CD001431.
10. Flory J, Emmanuel E. Interventions to improve research participants' understanding in informed consent for research: a systematic review. JAMA. 2004;292(13):1593-601.

11. Legare F, Politi MC, Drolet R, Desroches S, Stacey D, Bekker H, et al. Training health professionals in shared decision-making: an international environmental scan. Patient Educ Couns. 2012:88(2):159-69.

12. Morales A, Amir O, Lee L. Keeping it real in experimental researchunderstanding when, where, and how to enhance and meaure consumer behavior. J Consum Res. 2017:44(2):465-76.

13. Bostyn DH, Sevenhant S, Roets A. Of mice, men, and trolleys: hypothetical judgment versus real-life behavior in trolley-style moral dilemmas. Psychol Sci. 2018;29(7):1084-93.

14. Eastwick P, Hunt L, Neff L. External validity, why art thou externally valid? Recent studies of attraction provide three theoretical answers. Soc Personal Psychol Compass. 2013;7:275-88.

15. Grant MJ, Booth A. A typology of reviews: an analysis of 14 review types and associated methodologies. Health Inf Libr J. 2009;26(2):91-108.

16. Richardson WS, Wilson MC, Nishikawa J, Hayward RSA. The well-built clinical question: a key to evidence-based decisions. ACP J Club. 1995;123(3):A12-3.

17. Moher D, Liberati A, Tetzlaff J, Altman DG. Preferred reporting items for systematic reviews and meta-analyses: the PRISMA statement. PLoS Med. 2009;6(7):e1000097.

18. FeldmanHall O, Mobbs D, Evans D, Hiscox L, Navrady L, Dalgleish T. What we say and what we do: the relationship between real and hypothetical moral choices. Cognition. 2012;123(3):434-41.

19. Kuhberger A, Schulte-Mecklenbeck M. Framing decisions: hypothetical and real. Organ Behav Hum Decis Process. 2002;89(2):1162-75.

20. FeldmanHall O, Dalgleish T, Thompson R, Evans D, Schweizer S, Mobbs D. Differential neural circuitry and self-interest in real vs hypothetical moral decisions. Soc Cogn Affect Neurosci. 2012;7(7):743-51.

21. Galotti K. Approaches to studying formal and everyday reasoning. Psycho Bull. 1989;105(3):331-51.

22. Irwin J, McClelland G, Schulze W. Hypothetical and rel consequences in experimental auctions for insurance against low-probability risks. J Behav Decis Mak. 1992;5(2):107-16.

23. Morgenstern $\mathrm{R}$, Heldmann M, Vogt B. Differences in cognitive control between real and hypothetical payoffs. Theor Decis. 2013;77(4):557-82.

24. Slovic P. Differential effects of real versus hypothetical payoffs on choices among gambles. J Exp Psychol. 1969;80(3):434-7.

25. Taylor M. Bias and brains: risk aversion and cognitive ability across real and hypothetical settings. J Risk Uncertain. 2013;46(3):299-320.

26. Vlaev I. How different are real and hypothetical decisions? Overestimation, contrast and assimilation in social interaction. J Econ Psychol. 2012;33(5): 963-72.

27. McGowan J, Sampson M, Salzwwdel D, Cogo E, Foerster V, Lefebvre C. CADTH methods and guidelines: PRESS peer review of electronic search strategies: 2015 guideline explanation and elaboration (PRESS E\&E). Ottawa: CADTH; 2016.

28. Hsieh HF, Shannon SE. Three approaches to qualitative content analysis. Qual Health Res. 2005;15(9):1277-88.

29. Lynch EA, Mudge A, Knowles S, Kitson AL, Hunter SC, Harvey G. "There is nothing so practical as a good theory": a pragmatic guide for selecting theoretical approaches for implementation projects. BMC Health Serv Res. 2018;18(1):857

30. Mjelde JW, Jin YH, Lee CK, Kim TK, Han SY. Development of a bias ratio to examine factors influencing hypothetical bias. J Environ Manag. 2012;95(1): 39-48.

31. Day R. Relations between moral reasoning, personality traits, and justice decisions on hypothetical and real-life moral dilemmas. Diss Abstr Int Sect B Sci Eng. 1998;58(12-B):6795.

32. Lonnqvist J-E, Verkasalo M, Walkowitz G. It pays to pay-big five personality influences on co-operative behaviour in an incentivized and hypothetical prisoner's dilemma game. Pers Individ Di. 2011;50(2):300-4.

33. Grebitus C, Lusk J, Nayga R. Explaining differences in real and hypothetica experimental auctions and choice experiments with personality. J Econ Psychol. 2013:36:11-26.

34. Trevethan S, Walker L. Hypothetical versus real-life moral reasoning among psychopathic and delinquent youth. Dev Psychopathol. 1989;1:91-103.

35. Ajzen I, Brown T, Carvajal F. Explaining the discrepancy between intentions and actions: the case of hypothetical bias in contingent valuation. Personal Soc Psychol Bull. 2004;30(9):1108-21. 
36. Camerer $C$, Hogarth R. The effects of financial incentives in experiments: a review and capital-labor-production framework. J Risk Uncertain. 1999;19:742.

37. Camerer C, Mobbs D. Differences in behavior and brain activity during Hyupothetical and real choices. Trends Cogn Sci. 2017;21(1):46-56.

38. Ceccato S, Kettner SE, Kudielka BM, Schwieren C, Voss A. Social preferences under chronic stress. PLoS One. 2018;13(7):e0199528.

39. Chapman $\mathrm{G}$. The psychology of medical decision making. In: Koehler D, Harvey N, editors. Blackwell handbook of judgment and decision making. Malden: Blackwell Publishing; 2004. p. 587-603.

40. Kang MJ, Camerer CF. fMRI evidence of a hot-cold empathy gap in hypothetical and real aversive choices. Front Neurosci. 2013;7:104.

41. Joel S. Romantic relationship decisions: focusing on the role of the partner [dissertation]. Toronto: University of Toronto; 2015.

42. Teper R, Tullett AM, Page-Gould E, Inzlicht M. Errors in moral forecasting: perceptions of affect shape the gap between moral behaviors and moral forecasts. Personal Soc Psychol Bull. 2015:41(7):887-900.

43. Barkan R, Danzinger S, Shani Y. Do as I say, not as I do: choice-advice differences in decisions to learn information. J Econ Behav Organ. 2016;125: 57-66.

44. Morkbak M, Olsen S, Campbell D. Behavioral implications of providing real incentives in stated choice experiments. J Econ Psychol. 2014;45:102-16.

45. Holt C, Laury S. Risk aversion and incentive effects. SSRN Electron J. 2002; 95(5):1644-55

46. Holt C, Laury S. Risk aversion and incentive effects: new data without order effects. Am Econ Rev. 2005;95(3):902-4.

47. Xu S, Pan Y, Wang Y, Spaeth A, Qu Z, Rao H. Real and hypothetical monetary rewards modulate risk taking in the brain. Sci Rep. 2016;6:29520.

48. Xu S, Yu P, Qu Z, Fang Z, Yang Z, Yang F, et al. Differential effects of real versus hypothetical monetary reward magnitude on risk-taking behaviior and brain activity. Sci Rep. 2018:8:3712.

49. Verneau F, La Barbera F, Del Giudice T. The role of implicit associations in the hypothetical bias. J Consum Aff. 2017;51(2):312-28.

50. Little J, Berrens R. Explaining disparities between actual and hypothetical stated values: further investigation using meta-analysis. Econ Bull. 2004;3(6): $1-13$.

51. Murphy J, Stevens T. Contingent valuation, hypothetical bias, and experimental economics. J Agric Resour Econ. 2004:33(2):182-92.

52. Harrison G, Rutström E. Experimental evidence on the existence of hypothetical bias in value elicitation methods. In: Plott C, Smith v, editors. Handbook of Experimental Economics Results. North-Holland: Elsevier; 2008. p. 752-67.

53. Blumenschein K, Johannesson M, Yokoyama K, Freeman P. Hypothetical versus real willingness to pay in the health care sector: results from a field experiment. J Health Econ. 2001;20(3):441-57.

54. Johannesson M, Blomquist G, Blumenschein $K$, Johansson P, Liljas B, O'Conor R. Calibrating hypothetical willingness to pay responses. J Risk Uncertain. 1999;8:21-32.

55. Blumenschein $\mathrm{K}$, Johannesson M, Blomquist G, Liljas B, O'Conor R. Experimental results on expressed certainty and hypothetical bias in contingent valuation. South Econ J. 1998;65(1):169-77.

56. Hainmueller J, Hangartner D, Yamamoto T. Validating vignette and conjoint survey experiments against real-world behavior. PNAS. 2015;112(8):2395400.

57. Etchart-Vincent N, L'Haridon O. Monetary incentives in the loss domain and behavior toward risk: an experimental comparison of three reward schemes including real losses. J Risk Uncertain. 2011:42(1):61-83.

58. Beattie J, Loomes $\mathrm{G}$. The impact of incentives upon risky choice experiments. J Risk Uncertain. 1997:14:155-68.

59. Scholl J, Kolling N, Nelissen N, Wittmann MK, Harmer CJ, Rushworth MF. The good, the bad, and the irrelevant: neural mechanisms of learning real and hypothetical rewards and effort. J Neurosci. 2015;35(32):11233-51.

60. Harrison G. Hypothetical bias over uncertain outcomes. In: List JA, ed. Using experimental methods in environmental and resource economics. Northampton: Edward Elgar Publishing, Inc; 2006. p. 41-69.

61. Murphy J, Allen P, Stevens T, Weatherhead D. A meta-analysis of hypothetical bias in stated preference valuation. Environ Resour Econ. 2005; 30(3):313-25.

62. Levin I, Chapman D, Johnson R. Confidence in judgments based on incomplete information: an investigation using both hypothetical and real gambles. J Behav Decis Mak. 1988;1(1):29-41.
63. Gold N, Pulford B, Colman A. Do as I say, don't do as I do: differences in moral judgments do not translate into differences in decisions in real-life trolley problems. J Econ Psychol. 2015;47:50-61.

64. Skoe E, Eisenberg N, Cumberland A. The role of reported emotion in reallife and hypothetical moral dilemmas. Personal Soc Psychol Bull. 2002;28(7): 962-73.

65. Sacco J, Lillico HG, Chen E, Hobin E. The influence of menu labelling on food choices among children and adolescents: a systematic review of the literature. Perspect Public Health. 2017;137(3):173-81.

66. Anselme P. Does reward unpredictably reflect risk? Behav Brain Res. 2015; 280:119-27.

67. Klein SA, Hilbig BE. On the lack of real consequences in consumer choice research. Exp Psychol. 2019;66(1):68-76.

68. Hinvest NS, Anderson IM. The effects of real versus hypothetical reward on delay and probability discounting. Q J Exp Psychol. 2010;63(6):1072-84.

69. Müller $H$, Kroll E, Vogt B. Do real payments really matter? A re-examination of the compromise effect in hypothetical and binding choice settings. Mark Lett. 2012;23(1):73-92.

70. Patil I, Cogoni C, Zangrando N, Chittaro L, Silani G. Affective basis of judgment-behavior discrepancy in virtual experiences of moral dilemmas. Soc Neurosci. 2014;9(1):94-107.

71. List J, Gallet C. What experimental protocol influence disparities between actual and hypothetical stated values? Environ Resour Econ. 2001;20(3):24154.

72. Johansson-Stenman O, Svedsater H. Self-image and valuation of moral goods: stated versus actual willingness to pay. J Econ Behav Organ. 2012; 84(3):879-91.

73. Kesternich I, Heiss F, McFadden D, Winter J. Suit the action to the word, the word to the action: hypothetical choices and real decisions in Medicare part D. J Health Econ 2013:32(6):1313-24

74. Johnson DJ, Cesario J, Pleskac TJ. How prior information and police experience impact decisions to shoot. J Pers Soc Psychol. 2018;115(4):601-23.

75. Gold N, Colman A, Pulford B. Cultural differences in responses to real-life and hypothetical trolley problems. Judgm Decis Mak. 2014;9(1):65-76.

76. Ebbesen $\mathrm{E}$, Konecni $\mathrm{V}$. On the external validity of deicision making research: What do we know about decisions in the real world? In: Wallsten T. Cognitive processes in choice and decision behavior. Hillsdale: L Earlbaum Associates; 1980. p. 21-45.

77. Madden GJ, Begotka AM, Raiff BR, Kastern LL. Delay discounting of real and hypothetical rewards. Exp Clin Psychopharmacol. 2003;11(2):139-45.

78. Johnson MW, Bickel WK. Within-subject comparison of real and hypothetical money rewards in delay discounting. J Exp Anal Behav. 2002;77(2):129-46.

79. Lagorio $\mathrm{CH}$, Madden GJ. Delay discounting of real and hypothetical rewards III: steady-state assessments, forced-choice trials, and all real rewards. Behav Process. 2005:69(2):173-87.

80. Lawyer SR, Schoepflin F, Green R, Jenks C. Discounting of hypothetical and potentially real outcomes in nicotine-dependent and nondependent samples. Exp Clin Psychopharmacol. 2011;19(4):263-74.

81. Bickel WK, Jones BA, Landes RD, Christensen DR, Jackson L, Mancino M. Hypothetical intertemporal choice and real economic behavior: delay discounting predicts voucher redemptions during contingencymanagement procedures. Exp Clin Psychopharmacol. 2010;18(6):546-52.

82. Madden GJ, Raiff BR, Lagorio CH, Begotka AM, Mueller AM, Hehli DJ, et al. Delay discounting of potentially real and hypothetical rewards: II. Betweenand within-subject comparisons. Exp Clin Psychopharmacol. 2004;12(4):25161.

83. Silva FJ, Gross TF. The rich get richer: students' discounting of hypothetical delayed rewards and real effortful extra credit. Psychon Bull Rev. 2004;11(6): 1124-8.

84. Dixon MR, Lik NM, Green L, Myerson J. Delay discounting of hypothetical and real money: the effect of holding reinforcement rate constant. J Appl Behav Anal. 2013:46(2):512-7.

85. van Nieuwenhuijzen M, Bijman ER, Lamberix IC, Wijnroks L, de Castro BO, Vermeer $\mathrm{A}$, et al. Do children do what they say? Responses to hypothetical and real-life social problems in children with mild intellectual disabilities and behaviour problems. J Intellect Disabil Res. 2005:49(Pt 6):419-33.

86. Berinsky A, Huber G, Lenz G. Evaluating online labor markets for experimental research: Amazon.com's mechanical Turk. Polit Anal, 2012;20: 351-68.

87. Peterson R, Merunka D. Convenience samples of college students and research reproducibility. J Bus Res. 2014;67:1035-41. 
88. Peterson R. On the use of college students in social science research: insights from a second-order meta-analysis. J Consum Res. 2001;28(3):45061.

89. Payne J, Bettman J, Schkade D. Measuring constructed preferences: toward a building code. J Risk Uncertain. 1999;19(1-3):243-70.

90. Craig P, Dieppe P, Macintyre S, Michie S, Nazareth I, Petticrew M.

Developing and evaluating complex interventions: new guidance. Medical Research Council, London, 2008. Medical Research Council 2008.

91. Edwards PJ, Roberts I, Clarke MJ, Diguiseppi C, Wentz R, Kwan I, et al. Methods to increase response to postal and electronic questionnaires. Cochrane Database Syst Rev. 2009;3(3):MR000008.

92. Treweek S, Pitkethly M, Cook J, Fraser C, Mitchell E, Sullivan F, et al. Strategies to improve recruitment to randomised trials. Cochrane Database Syst Rev. 2018;2:MR000013.

\section{Publisher's Note}

Springer Nature remains neutral with regard to jurisdictional claims in published maps and institutional affiliations.

Ready to submit your research? Choose BMC and benefit from:

- fast, convenient online submission

- thorough peer review by experienced researchers in your field

- rapid publication on acceptance

- support for research data, including large and complex data types

- gold Open Access which fosters wider collaboration and increased citations

- maximum visibility for your research: over $100 \mathrm{M}$ website views per year

At $\mathrm{BMC}$, research is always in progress.

Learn more biomedcentral.com/submissions 